\title{
Dangerous settings and risky international assignments
}

\section{Introduction}

An increasing number of people are engaging in roles and jobs that involve international mobility under higher danger and risk, such as business expatriates, military, health, emergency and rescue service providers, development aid volunteers and peacekeepers, journalists, diplomats, religious missionaries etc. Yet, until now, we have only a limited understanding on how the intensification of risks affects international mobility. Previous research has focused on the physical and psychological hazards of certain occupational groups, such as military (e.g. Fisher, Hutchings and Pinto, 2015) and war journalists/correspondents (e.g. Feinstein, Owen and Blair, 2002). Other studies have considered the HRM issues of hostile environments abroad (e.g. Bader and Schuster, 2015, Reade and Lee, 2012) and revealed that terrorism-related threats can cause stress and impair expatriates' attitudes and performance (Bader and Berg, 2013, 2014) or have shown the beneficial effects of expatriates' families and organizational support (Bader, Berg and Holtbrügge, 2015). However, despite these contributions and recent developments in the understanding of multiple forms of international mobility (Mayrhofer and Reiche, 2014; Shaffer et al., 2012), this field is still in its infancy. In fact, there is only limited knowledge about the characteristics of people who work in dangerous and remote areas, such as offshores, war zones, humanitarian, and emergency settings. In addition, less is known about how they work in these environments and which specific threats they perceive and face. This is surprising, given the practical importance these questions have for global mobility in daily life. Therefore, this special issue aims at addressing these issues and, in particular, contribute to the knowledge about (1) the forms of danger and risk and how to conceptually and 
empirically distinguish them; (2) the drivers that lead people to work and live in dangerous settings, (3) the challenges of adjusting to living and working conditions in these settings, and (4) the outcomes of danger and fear to adjustment, well-being, and further willingness to relocate. This special issue, and another soon to be published (Bader, Schuster and Dickmann, 2019) underscore the increasing interest and importance of investigating the elements of working abroad in dangerous and risky locations and occupations. With regard to the developments in an increasingly VUCA world, an acronym used to describe the volatility, uncertainty, complexity, and ambiguity of a situation, this may be the beginning of this research stream making its way into mainstream research.

\section{Articles in this special issue}

The articles in this special issue are from different conceptual and methodological backgrounds and cover a broad variety of sub-topics in this research stream. They are grounded in a variety of theoretical frameworks, such as intelligent careers perceptive, expectancy value theory, transactional model of coping, social identity theory, cultural adjustment model, and compliance with social norms. Methodologically, the studies adopted both qualitative and quantitative approaches, though unsurprisingly, qualitative approaches dominate given the specific research questions addressed and the early stage of development of the field. The samples range from business expatriates living in safe countries to those working in particularly dangerous locations, such as Kenya and South Africa, and expatriates working in host countries of high terrorist threat or pervasive corruption. Apart from business expatriates, the samples cover non-profit organization employees displaced in hostile environments as well. This diversity seeks to expand our existing knowledge of the multiple forms of danger and risk. 
The first article, "I might be shot at"! Exploring the drivers to work in hostile environments using an intelligent careers perspective," written by Michael Dickmann and Ashley Watson, adopts a qualitative approach and a 'deviate' case study method to explore the factors that drive the 25 employees of a not-for-profit international organization to work and live in hostile environments. The authors use the descriptor "hostile environments" to name the areas "where the government cannot, or will not, deliver core functions to the people including to the poor," which raise the risks for locals and consequently the need to provide international assistance and deploy international assignees. In highly risky locations, such as South Sudan, Democratic Republic of Congo, Afghanistan and Pakistan, the security and health considerations requiring international assistance might dissuade the acceptance of an assignment. While the results confirm the key individual, organizational, and location-specific reasons to accept an assignment to safer environments, the findings also expand existing intelligent careers literature by showing that the higher levels of risk at destination lead to wider and faster insights and learning, stronger personal networks, faster promotion opportunities including the transfer of career capital beyond the organization to government. Furthermore, the findings of this study highlight the importance of specific location issues related to the support and trust in the host management team as decisional factors. When people feel they "may be shot at," they need to trust the host country office and local line managers, for which their reputation is of paramount consideration. These findings have significant implications for research and practice as further discussed below.

Continuing with the theme of the willingness to relocate to dangerous settings, the second article is "For sensation's sake: Differences in female and male expatriates' relocation willingness to dangerous countries based on sensation seeking" by Sebastian Stoermer, Samuel Davies, Oliver Bahrisch, and Fedor Portniagin. Applying the expectancy value 
theory, the authors examine how individual factors, such as expatriates' gender and sensation seeking behaviour defined as the desire to take diverse experiences and accept related risks, explain the relocation willingness to dangerous countries. The findings are based on a crosssectional survey of 148 organizational and self-initiated expatriates currently residing in safe countries. The study reveals that male expatriates are more willing to relocate to dangerous destinations due to a higher sensation seeking behaviour than females, while money orientation does not condition this relationship. The authors focus on the practical implications of these findings for recruiting, selecting, and retaining the individuals eligible to relocate to dangerous environments. Further empirical research with different samples of business expatriates and various country risks might validate the results of this study.

The third article, "How do you fear? Examining expatriates' perception of danger and its consequences," authored by Pia Faeth and Markus Kittler, addresses the differing perceptions of fear in contexts of conventional crime that assignees experienced in Johannesburg and terrorism in Nairobi. The authors start by conceptually distinguishing terrorism from conventional crime to provide a workable differentiation. Subsequently, by following an interpretative and inductive approach, they interviewed 12 expatriates from an international financial institution occupying senior management positions in these locations, to reveal that fear perceptions are stronger in terrorism exposed contexts (e.g. Nairobi) than in environments of conventional crime (e.g. Johannesburg). Since fear restricts the freedom of movements in both contexts, it affects expatriates' physical health and to a lower extent expatriates' mental well-being, but does not decrease the level of reported happiness. When it comes to coping in these distinctive contexts, the findings reveal that, expatriates use avoidance-coping strategies to deal with the fear from terror whereas they use problemfocused coping strategies to handle the fear from crime. This study provides an in-depth look 
at two distinct but dangerous contexts characterized by terrorism and conventional crime and the challenges they pose to business expatriates, including the specific consequences for stress, well-being, and coping.

The fourth article, "Host country language skills and expatriates' cross-cultural adjustment in the presence of fear of terror," authored by Philipp Paulus and Katrin Muehlfeld, examines the relationship between expatriates' host language proficiency and cross-cultural adjustment in terrorism-endangered environments. Language is a crucial success factor for each and every assignment. With survey data from 116 business expatriates based in locations with different levels of terrorism threat, the authors found that while expatriates host language fluency is positively associated with cross-cultural adjustment, the level of proficiency in the host language also imply heightened sensitivity to fear of terror. They hence show that the role of language is even more important in settings where the expatriate is assigned to a dangerous host country. Moreover, incorporating cross-cultural adjustment, the study looks at one of the most important outcome variables in expatriate research and puts it into a new context. Therefore, their study complements previous research on international assignments in terrorism-endangered environments and favorably extends the emerging research in the field.

The fifth article, "How US expatriates work in (dangerous) environments of pervasive corruption?” by Carl Greppin, Bo Carlsson, Adrian Wolfberg, and Nnaoke Ufere, focus on a distinct and yet under-researched topic of fear and threat associated to locations of pervasive corruption. By interviewing 30 US business expatriates displaced in countries of pervasive corruption the authors show how corruption constitutes a form of danger and a source of threat and fear that undermines expatriates' decision-making. In coping with the phenomena, the interviewed expatriates outline how they balanced reasons for three options for action: 
zero tolerance to corruption, reactively succumb to extortion or proactively participate, based on distinct social norms. In spite of these distinct decisions, all expatriates reported emotional pain, fear and social anxiety which underscores other facets of danger and risk.

\section{Contributions and future research}

Drawing on the articles from this special issue, four key contributions are highlighted and then related to suggestions for future research.

First, the articles from this special issue help to clarify some forms of 'danger and risk' and provide workable conceptual distinctions that others may extend and empirically test in the future. For instance, Dickmann and Watson (2017, p. 14) adopt the construct of 'hostile environments' also referred as 'fragile environments' (...) to define the "areas where the government cannot, or will not, deliver core functions to the people including the poor; while Faeth and Kittler (2017) make attempts to distinguish terrorism from conventional crime. By establishing this distinction, the authors aim to understand how expatriates perceive the challenges and fear associated to living conditions that are uncomfortable but allow for different degrees of control. While conventional crime "refers to a non-terrorism form of criminal activity, mainly crimes that are personal offenses such as (armed) robbery, raid, rape, or hijacking, and any property offenses such as carjacking, or break-ins" (Faeth and Kittler, p. 6), terrorism is the "term associated with more or less organized groups (or 'movements') that act violently and deliberately against target civilians intending to create fear and harm beyond the direct victims and perpetrated with an interplay of motivational drivers, such as political, religious, honour, poverty, group pressure, personal significance etc." (Faeth and Kittler, 2017, p. 5). The authors argue that individuals fear both conventional crime and terrorism, but because terror and terrorism are potentially more destructive of the social order and less controllable than conventional crime, it has a distinct and more negative influence over 
expatriates and organizations. These findings require further research with other locations and larger samples both beyond and within the field of business expatriation. Similarly, Dickmann and Watson (2017) note that the literature still overlooks the drivers to live in specific locations (cities vs. remote areas) including the safer ones, which is another opportunity for continuing research. Therefore, future research may empirically investigate how distinct forms of danger and risk are attractive or aversive to certain individuals (e.g. high in sensation seeking, self-efficacy, future time-orientation) as well as how other variables, such as reputation, organizational support, or financial incentives may relate to one another.

Moreover, as the studies provide initial evidence that different forms of risk and danger are perceived differently and have different consequences for expatriates, it seems reasonable that future studies investigate the effectiveness of applied HRM instruments depending on specific "risk categories" in order to provide organizations guidance on which HRM instruments should be employed.

Second, the articles also respond to earlier calls to contextualize expatriate research, thus all emphasize and empirically illustrate the relevance of the international assignment's context. Methodologically, the articles in this issue target different kinds of samples both in terms of locations as well as composition. Despite this diversity, all studies except one surveyed business expatriates (McNulty and Brewster, 2017), which highlight the importance of pursuing the effort of gaining insights from other expatriate communities through disciplines other than careers, international business, and international human resource management.

Third, following earlier calls (McNulty, Vance, and Fisher, 2017), the articles of this special issue increase the understanding of drivers to relocate to dangerous locations and greatly contribute to address the particularities of and the differences between for-profit and 
not-for profit assignments and the differences of the respective assignees, which hopefully trigger additional research about dangerous occupations in the field of global mobility. Several occupational groups remain overlooked (McNulty, Vance, and Fischer, 2017), such as diplomats, temporary international aid workers, military, international volunteering and religious expatriates, so these and other communities constitutes opportunities for further research.

Fourth, and despite an extensive base of literature about expatriates' cross-cultural adjustment, there is still a limited understanding of the factors influencing cross-cultural adjustment in extreme contexts, which is a specific contribution of two of the studies included in this special issue. Furthermore, and adding to this theme, the article by Greppin, Carlsson, Wolfberg, and Ufere (2017) opens a new perspective about danger and risk and shows how working and living in countries of pervasive corruption constitute a major source of strain and stress that challenges expatriates' adjustment and identity. Dangerous locations known for terrorism, conventional crime, pervasive corruption, and lack of governance and governmental support can create such a reputation that not only provide a source of strain and stress to expatriates and their families but also challenge organizational policies and practices. Thus, more research is warranted to better understand the challenges they pose to multiple stakeholders and how reputational issues might limit global mobility.

\section{Conclusion}

This special issue offers much progress in understanding the multiple forms and contexts of global danger and risk, providing further conceptual development and differentiation, required to proceed the research in this domain. It is a first start to move this important research stream forward into mainstream research. As illustrated, people are triggered by multiple drivers to accept dangerous assignments, and yet novel features are introduced, such as gender and 
sensation seeking behaviour, host-location reputation and trust in the local management. Another insight refers to how different forms of danger trigger distinctive fear perceptions that are associated to different outcomes, such as expatriates stress, wellbeing and coping. Equally illustrative is the form through which host language fluency not only influences expatriates' cross-cultural adjustment as may undermine it in terrorism-endangered environments. Finally, locations of pervasive corruption constitute contexts of danger and threat that are worth of further research. As demonstrated by all these articles, this is a promising stream of research, hopefully open to other theoretical disciplines and new and innovative designs.

\section{Acknowledgments}

We would like to express great thanks to the many scholars who provided support in compiling this special issue, most importantly during the review process. Their thorough and thoughtful reviews helped the authors to further improve their manuscripts and guided us in our judgment. Moreover, we would like to express our thanks to Jan Selmer and the editorial team of Journal of Global Mobility: The Home of Expatriate Management Research for their unresting support. We and the authors hope that the readers see the same in the special issue that we do: valuable as well as stimulating for new work in this important field. 


\section{References}

Bader, B. and Berg, N. (2013), 'An empirical investigation of terrorism-induced stress on expatriate attitudes and performance', Journal of International Management, Vol. 19 No. 2, pp. 163-175.

Bader, B., \& Berg, N. (2014), 'The Influence of Terrorism on Expatriate Performance: a Conceptual Approach', International Journal of Human Resource Management, 25(3-4), 539-557.

Bader, B., Berg, N., \& Holtbrügge, D. (2015), 'Expatriate performance in terrorismendangered countries: The role of family and organizational support', International Business Review, 24(5), 849-860.

Bader, B. and Schuster, T. (2015), 'Expatriate Social Networks in Terrorism-Endangered Countries: An Empirical Analysis in Afghanistan, India, Pakistan, and Saudi Arabia', Journal of International Management, Vol. 21 No. 1, pp. 63-77.

Bader B., International Journal of Human Resource Management T., \& Dickmann, M. (2019), 'Danger and risk as challenges for HRM: how to manage people in hostile environments Special Issue, International Journal of Human Resource Management.

Feinstein, A., Owen, J. and Blair, N. (2002), 'A Hazardous Profession: War, Journalists, and Psychopathology', American Journal of Psychiatry, Vol. 159 No. 9, pp. 1570-1575.

Fisher, K., Hutchings, K. and Pinto, L. H. (2015), 'Pioneers across war zones: The lived acculturation experiences of US female military expatriates', International Journal of Intercultural Relations, Vol. 49, pp. 265-277

Mayrhofer, W. and Reiche, S. B., (2014), 'Guest editorial: context and global mobility: diverse global work arrangements’, Journal of Global Mobility, Vol. 2 No. 2.

McNulty, Y., and Brewster, C. (2017), Chapter 2: The concept of business expatriates. In Y. McNulty \& J. Selmer (Eds.), Research Handbook of Expatriates (pp. 21-60). Cheltenham, UK: Edward Elgar.

McNulty, Y., Vance, C. V and Fisher, K., (2017), 'Guest editorial: Beyond corporate expatriation - global mobility in the sports, religious, education and non-profit sectors', Journal of Global Mobility: The Home of Expatriate Management Research, Vol. 5 No. 2, pp.110-122, https://doi.org/10.1108/JGM-04-2017-0014

Reade, C. and Lee, H. J. (2012), 'Organizational Commitment in Time of War: Assessing the Impact and Attenuation of Employee Sensitivity to Ethnopolitical Conflict', Journal of International Management, Vol. 18 No. 1, pp. 85-101. 
Shaffer, M. A., Kraimer, M. L., Chen, Y. P. and Bolino, M. C. (2012), 'Choices, Challenges, and Career Consequences of Global Work Experiences', Journal of Management, Vol. 38 No. 4, pp. 1282-1327. 